\title{
4QReworked Pentateuch C and the Literary Sources of the Temple Scroll: A New (Old) Proposal $^{1}$
}

\begin{abstract}
This essay proposes a new understanding of the literary history of the Temple Scroll in light of its relationship with 4QReworked Pentateuch C (4Q365 + 365a). It begins from the argument that 4QRP C includes the five fragments labeled 4Q365a (4QTemple?), and that 4QRP C should be regarded as an expanded edition of the Pentateuch. Substantial parallels between 4QRP C (both 4Q365 and 4Q365a) and the Temple Scroll raise the possibility that an expanded Pentateuch resembling 4QRP C could have constituted the main source with which the Temple Scroll's redactor worked. This proposal departs from the usual understanding of the Scroll as comprised of several lightly-reworked, independent sources. Instead, it situates the composition of the Temple Scroll more firmly in the context of the ongoing scribal reworking of scripture in the Second Temple period.
\end{abstract}

Keywords: Temple Scroll, 4QReworked Pentateuch, 4Q365, 4Q365a, scriptural rewriting, variant literary editions

From very early in the history of research on the Temple Scroll (TS), the Scroll's own literary history has received substantial attention. Yigael Yadin himself recognized the possibility that parts of the Scroll existed in another form prior to its redaction. ${ }^{2}$ Yadin did not pursue this line of inquiry, but already in 1982 Andrew Wilson and Lawrence Wills published their influential proposal that the Scroll consisted of a lightly-redacted combination of five literary sources that had originally existed independently. ${ }^{3}$ Michael Wise introduced important modifications to this theory, assigning more material to the redactor of the Scroll. ${ }^{4}$ Other scholars since then have made further advancements, notably Lawrence Schiffman, with his suggestion that the rewriting

${ }^{1}$ This paper originated in a presentation given in a special session devoted to the Temple Scroll at the 2010 ASOR annual meeting in Atlanta, Georgia. I am grateful to C. D. Elledge and James Charlesworth for inviting me to contribute to that session, and to the session participants, especially Larry Schiffman, for valuable feedback. I also thank Peter Grund and Dan Machiela for their comments on earlier drafts. Special thanks are due to Sidnie White Crawford not only for many thoughtful comments on a draft, but also for her generosity in several conversations pertaining to my proposal and in providing me with a pre-publication copy of her recent paper on the 4Q365a fragments (see n. 14 below).

2 Yigael Yadin, The Temple Scroll (3 vols.; Jerusalem: Israel Exploration Society,1977-83), 1.390.

${ }^{3}$ Andrew M. Wilson and Lawrence Wills, "Literary Sources of the Temple Scroll," HTR 75 (1982): 27588.

${ }^{4}$ Michael Owen Wise, A Critical Study of the Temple Scroll from Qumran Cave 11 (SAOC 49; Chicago: Oriental Institute of the University of Chicago, 1990). 
of Deuteronomic law in the latter third of TS does not represent a preexisting source but was produced by the Scroll's redactor. ${ }^{5}$ The idea that TS draws upon multiple independent prior sources appears to have been widely accepted, and has been promoted not only in Schiffman's many writings on the Scroll, but also in introductory materials such as Sidnie White Crawford's volume The Temple Scroll and Related Texts and Florentino García Martínez's article on TS in the Encyclopedia of the Dead Sea Scrolls. ${ }^{6}$

Apart from this literary analysis of the main copy of the Scroll, 11Q19, the idea that TS likely had a long history of development is supported by the evidence of several other Qumran manuscripts. While a second copy of TS from Cave $11\left(11 \mathrm{Q} 20=11 \mathrm{QTemple}{ }^{\mathrm{b}}\right)$ seems to have differed little from the main copy, the Cave 4 ms 4Q524 (=4QRT) appears to represent either a different, perhaps earlier, recension of TS, or a source for TS. ${ }^{7}$ In addition, important evidence for TS's prehistory is provided by the manuscript 4Q365 + 365a, 4QReworked Pentateuch C (4QRP C). ${ }^{8}$ One of the fragments of this manuscript contains substantial textual overlaps with two columns of TS dealing with the construction of temple courts. Another fragment is thematically, and perhaps textually, connected with TS through its mention of a six-day period in which wood is brought, tribe by tribe, for the upkeep of the temple and the sacrificial altar. These

${ }^{5}$ Lawrence H. Schiffman, “The Deuteronomic Paraphrase of the Temple Scroll,” RevQ 15 (1992): 543-67.

${ }^{6}$ Schiffman's articles on TS are now conveniently available in Lawrence H. Schiffman, The Courtyards of the House of the Lord: Studies on the Temple Scroll (ed. F. García Martínez; STDJ 75; Leiden: Brill, 2008); for a summary of his views on the Scroll's composition, see pp. 4-5. See also Sidnie White Crawford, The Temple Scroll and Related Texts (Sheffield: Sheffield Academic Press, 2000), 23; eadem, Rewriting Scripture in Second Temple Times (Grand Rapids: Eerdmans, 2008), 89-93; Florentino García Martínez, "Temple Scroll," in Encyclopedia of the Dead Sea Scrolls (ed. L. H. Schiffman and J. C. VanderKam; 2 vols.; Oxford: Oxford University Press, 2000), $927-33$, at 929.

${ }^{7}$ Various proposals exist for understanding the relationship between 4Q524 and the main copy of TS (11Q19), from seeing 4Q524 as a copy of TS to regarding it as a source or merely a related composition; for a recent overview see James H. Charlesworth, "Temple Scroll Source or Earlier Edition (4Q524 [4QT'; 4QRT])," in L. H. Schiffman et al., Temple Scroll and Related Documents (Princeton Theological Seminary Dead Sea Scrolls Project 7; Lexington: Westminster John Knox, 2011), 247-65, at 249-50.

${ }^{8}$ The siglum 4Q365a represents a group of five fragments that the DJD editors of 4Q365 judged to belong to a different manuscript on the basis of their contents. As I will argue extensively below, however, these five fragments should be regarded as part of 4Q365. 
two fragments were regarded by Yadin as part of an additional copy of TS, and by Michael Wise as part of a "proto-Temple Scroll" that served as a source for the Scroll's final redactor. ${ }^{9}$ But the full publication of this manuscript has made clear that the fragments are not part of the Temple Scroll but rather belong to a different composition altogether: the group of five manuscripts titled 4QReworked Pentateuch. ${ }^{10}$ 4QRP C preserves portions of the Pentateuch from Genesis to Deuteronomy, often matching the text as known from elsewhere, but often attesting previously unknown additions, rearrangements, and other types of modifications.

I would like to suggest that this manuscript, 4QRP C, can contribute a great deal to our understanding of the composition and literary history of TS. In fact, on the basis of this manuscript I believe an alternative model for the Scroll's composition should be proposed. Instead of combining several already-existing independent sources with his own rewritten version of the scriptural text, it is possible that the redactor worked primarily with a single source document, and that this document was a version of the Torah that - like the version that we find in 4QRP C - had itself already undergone substantial rewriting. Furthermore, I propose that the possibility should be seriously considered that this rewritten pentateuchal Vorlage used by TS was in fact the version represented by $4 \mathrm{QRP} C$, or one very similar to it. The following study first presents the evidence for regarding 4QRP C (=4Q365 +365a) as a pentateuchal manuscript, and then explores how this understanding of 4QRP C in turn provides the basis for a different understanding of the Temple Scroll.

To my knowledge, this particular proposal for understanding TS has not previously been presented in detail. However, various related suggestions have been made. On the one hand, once

\footnotetext{
${ }^{9}$ Yadin, Temple Scroll, 1.8-9, 123; 2.172-73; and plates *38 and *40; Wise, Critical Study, 44-59.

${ }^{10}$ See Emanuel Tov and Sidnie White (Crawford), "4Q365," in DJD 13:255-318. Although the official publication labels these mss 4QReworked Pentateuch ${ }^{\mathrm{a}-\mathrm{e}}$, recent research has shown that they should be regarded as related works rather than copies of a single composition. See Molly M. Zahn, Rethinking Rewritten Scripture: Composition and Exegesis in the 4QReworked Pentateuch Manuscripts (STDJ 95; Leiden: Brill, 2011 ), $129-33$.
} 
it was realized that the two 4Q fragments with strong parallels to TS in fact belonged to a different, larger manuscript (4Q365), it was suggested that this manuscript may have constituted a source for TS. ${ }^{11}$ Yet these proposals did not address the possibility that 4Q365 may have represented the pentateuchal Vorlage of TS; here I will argue, building on recent studies of the 4QRP mss, that 4Q365 (including 4Q365a) most likely constitutes an expanded edition of the Pentateuch and therefore itself could have served as the basis for TS's rewriting of scripture. ${ }^{12}$ On the other hand, several scholars have implicitly or explicitly distanced themselves from the popular source-critical understanding of TS by stressing the Scroll's exegetical rewriting of the Torah. ${ }^{13}$ None of these studies, though (my own included), seriously consider the possibility that the version of the Torah that the redactor used might have differed substantially from the Masoretic text; by the same token, they do not attempt an explanation for the textual overlaps between TS and 4QRP C. The contribution of this study, then, lies in the integration of a view of 4QRP C as a pentateuchal manuscript containing substantial expansions - including instructions for the building of temple courts_-into the discussion concerning the literary history of TS.

Even in the narrow sense just outlined, the proposal offered here is not entirely new (as the title of this study is meant to suggest). The idea that 4QRP C may constitute the pentateuchal

${ }^{11}$ García Martínez, "Temple Scroll,” 928; Crawford, Temple Scroll, 55; eadem, Rewriting Scripture, 51. Note that the positions of these two scholars regarding the relationship of the 4Q365a fragments to 4Q365 differ: García Martínez argues that they belong together, while Crawford until recently has viewed the 4Q365a fragments as remnants of a different composition. (On the relationship of the fragments, see further below.)

${ }^{12}$ Lange in the first volume of his handbook on the Qumran Scrolls notes briefly in his discussion of 4Q365 that this manuscript - which he views as pentateuchal and as including the 4Q365a fragments - constitutes a source for TS; see Armin Lange, Handbuch der Textfunde vom Toten Meer, Band 1 (Tübingen: Mohr Siebeck, 2009), 37, 40. He thus anticipates the conclusion of the arguments I will make here.

13 Though Swanson nominally accepts the source-critical approach, the results of his study undermine that understanding of TS by demonstrating the consistency across TS in the methods by which scriptural texts are reworked; see Dwight D. Swanson, The Temple Scroll and the Bible: The Methodology of 11QT (STDJ 14; Leiden: Brill, 1995), 237. See also Molly M. Zahn, "Schneiderei oder Weberei? Zum Verständnis der Diachronie der Tempelrolle," RevQ 20 (2001): 255-86; Bernard M. Levinson and Molly M. Zahn, "Revelation Regained: The Hermeneutics of כי אם in the Temple Scroll," DSD 9 (2002): 295-346; C. D. Elledge, The Statutes of the King: The Temple Scroll's Legislation on Kingship (11Q19 LVI 12-LIX 21) (CahRB 56. Paris: Gabalda, 2004); Simone Paganini, "Nicht darfst Du zu diesen Wörtern etwas hinzufügen": die Rezeption des Deuteronomiums in der Tempelrolle: Sprache, Autoren und Hermeneutik (BZABR 11; Wiesbaden: Harrassowitz, 2009). 
Vorlage of TS, to which I was led in the course of my own work on TS and on the 4QRP mss, was in fact raised preliminarily by John Strugnell nearly three decades ago. ${ }^{14}$ In a letter published by Florentino García Martínez in 1986, Strugnell notes that the few fragments from 4QRP C that Yadin published as possibly representing another copy of TS in fact belonged to "a wildly aberrant text of the whole Pentateuch," and that the Scroll likely drew upon this text:

My ms. of which only a bit was published by Yadin...is a Middle Hasmonean copy of a wildly aberrant text of the whole Pentateuch containing several non-Biblical additions... It is more likely that these additions were copied by 11QTemple from an expansionist text of the Pentateuch rather than that my biblical scroll incorporated excerpts from the Temple Scroll. ${ }^{15}$

It is not clear whether Strugnell meant to suggest, as I will, that 4QRP C or a text very like it constituted the sole pentateuchal Vorlage for TS, or whether he meant simply that, at the points where they overlap, the Scroll has drawn selectively upon a text like 4QRP C. But the basic premise that TS has drawn upon 4QRP C, and that 4QRP C represents an already-expanded version of the Torah, is very close to the proposal I will outline below. As I will demonstrate, a variety of factors combined to cause scholarship on these texts to move in other directions, and Strugnell's proposal has generally been overlooked. ${ }^{16}$ In essence, then, my study recovers and

${ }^{14}$ I learned about this letter from Sidnie White Crawford, “4QTemple? (4Q365a) Revisited," in Prayer and Poetry in the Dead Sea Scrolls and Related Literature (ed. J. Penner, K. Penner, and C. Wassen; STDJ 98; Leiden: Brill, 2012), 87-96, at 88. I am grateful to Dr. Crawford for sharing a copy of her paper with me prior to its publication.

15 John Strugnell, letter cited according to Florentino García Martínez, 'La 'Nueva Jerusalén' y el Templo Futuro en los MSS de Qumrán,” in Salvación en la Palabra. En Memoria de A. Díez Macho (ed. D. Muñoz León; Madrid: Cristiandad, 1986), 563-90, at 563-64 (emphasis mine). García Martínez also discusses this letter briefly in idem, "Sources et rédaction du Rouleau du Temple," Henoch 13 (1991): 219-32, at 224. The precise date of this letter is unclear, but Prof. García Martínez has kindly confirmed that it must have been sent in 1983 or 1984 (personal communication, January 2012).

${ }^{16}$ Interestingly, an earlier comment by Strugnell regarding the relationship between 4Q365 and TS received somewhat more attention in the first decade of research on TS. In a 1981 letter to Ben Zion Wacholder, as in the later letter to García Martínez, Strugnell indicates that the Cave 4 fragments published by Yadin as a possible copy of TS in fact belong to a "Pentateuch with frequent non-biblical additions." In this letter, however, Strugnell expresses uncertainty about the nature of the relationship between the two texts: "whether they are quotations from the Temple Scroll incorporated by that Pentateuch, or vice versa (i.e. bits of an earlier 'wild' Pentateuch text used as a source by 11QT) remains to be seen." (Letter of 28 April 1981, quoted by Ben Zion Wacholder in The Dawn of Qumran: The Sectarian Torah and the Teacher of Righteousness [Cincinnati: Hebrew Union College Press, 1983], 206.) Strugnell's uncertainty was exploited in opposite ways by Wacholder and Hartmut Stegemann: after quoting 
fleshes out Strugnell's proposal in light of advances made in the last thirty years and thus sheds new light on both 4QRP C and TS. At the same time, my unwitting recapitulation of Strugnell's original assessment raises broader, and rather humbling, questions about how newly-discovered texts are classified, labeled, and understood, and how seemingly minor decisions regarding nomenclature or categorization can shape scholarship in major ways.

\section{The Nature and Contents of 4 Q365}

The suggestion that 4QRP C could possibly represent the pentateuchal Vorlage of TS is predicated upon a specific understanding of this manuscript in two respects: first, that 4QRP C includes the five fragments published in DJD 13 as 4Q365a; and second, that it constitutes a copy of the Pentateuch. Each of these issues has been disputed and therefore requires some elaboration.

\section{The 4Q365a Fragments}

Five of the fragments that had been identified by Strugnell, their original editor, as belonging to 4Q365 (=4QRP C) were removed from this manuscript by the official editors, Emanuel Tov and Sidnie White Crawford, and construed as constituting a separate composition, which was then given the siglum 4Q365a. Although all physical indications- - hand, leather, etc. - were the same for these five fragments as for the rest of $4 \mathrm{Q} 365$, these five, unlike the others, contained no pentateuchal material. Operating upon the assumption that $4 \mathrm{Q} 365$ was a rewritten version of the Pentateuch with relatively minor additions, the editors concluded that

\footnotetext{
Strugnell's letter, Wacholder draws the conclusion that is most amenable to his theory concerning the date and influence of TS: "the Rockefeller fragments appear to be citations from the sectarian Torah [= W.'s term for TS] superimposed on the traditional Pentateuch..." (ibid.). Stegemann, on the other hand, uses Strugnell's observation as support for his theory that TS collects together material from expanded Torahs that risked being lost after the canonization of the Torah in its short (= Masoretic) form in the days of Ezra, thus viewing 4Q365 as earlier than TS; Hartmut Stegemann, "The Origins of the Temple Scroll," in Congress Volume Jerusalem 1986 (ed. J. A. Emerton; VTSup 40; Leiden: Brill, 1988) 235-56, at 251-54.
} 
fragments with no biblical material were not likely to have been a part of the "parabiblical" composition represented by the rest of $4 \mathrm{Q} 365 .{ }^{17}$ This decision bears particular weight for consideration of the relationship between 4QRP C and TS because among the five fragments assigned to 4Q365a is the one that contains substantial verbatim overlap with TS (4Q365a fr. 2). ${ }^{18}$ In fact, because of this close association, 4Q365a was given the tentative title “4QTemple?." The question mark, as Crawford notes in her edition, reflects the fact that the five fragments cannot all be fit into the known text of TS; thus 4Q365a would have to represent a different recension of TS than the one appearing in $11 \mathrm{Q} 19 .{ }^{19}$

If the fragment with the strongest literary connection to TS does not actually belong to 4QRP C, then it makes little sense to argue that 4QRP C may represent (or closely resemble) the pentateuchal Vorlage of TS. However, Tov and Crawford's attribution of the five 4Q365a fragments to a separate composition has been called into question. As García Martínez has noted, there is no physical evidence to support such a separation, and making the a priori judgment that the composition represented by 4Q365 could not have contained substantial amounts of nonbiblical material would require an understanding of the nature and purpose of this text that we cannot presume to have. ${ }^{20}$ That is, the only thing preventing 4Q365 from having contained extended sections of nonbiblical material is the editors' assumption that it could not have contained such material. Given this situation, it seems much more prudent to follow the physical

\footnotetext{
${ }^{17}$ See Sidnie Ann White (Crawford), “4Q365a," in DJD 13:319-33, at 319; for a more thoroughgoing discussion, see eadem, "Three Fragments from Qumran Cave 4 and Their Relationship to the Temple Scroll," JQR 85 (1994): 259-73. This re-assignation of the five 4Q365a fragments on the basis of content has recently been followed by James H. Charlesworth, "Temple Scroll Source or Divergent Copy (4Q365a)," in L. H. Schiffman et al., Temple Scroll and Related Documents (Princeton Theological Seminary Dead Sea Scrolls Project 7; Lexington: Westminster John Knox, 2011), 235-45.

${ }^{18}$ For details see further below.

${ }^{19}$ White (Crawford), DJD 13:320, 329.

${ }^{20}$ Florentino García Martínez, "Multiple Literary Editions of the Temple Scroll?," in The Dead Sea Scrolls: Fifty Years After Their Discovery (ed. L. H. Schiffman, E. Tov, and J. C. VanderKam; Jerusalem: Israel Exploration Society/Shrine of the Book, Israel Museum, 2000), 364-71, at 369-70.
} 
evidence and regard the 4Q365a fragments as part of the larger composition reflected in 4Q365, unless more compelling evidence to the contrary comes along. ${ }^{21}$

In a recent article, one of the original editors, Sidnie White Crawford, revisits the issue of the 4 Q365a fragments. ${ }^{22}$ She rejects her previous suggestion that these fragments may belong to an alternate recension of TS, and notes that the physical evidence constitutes a powerful argument for viewing them as belonging to $4 \mathrm{Q} 365$. Crawford argues, however, that the association of the 4Q365a fragments with 4Q365 must remain tentative, because it is difficult to locate the 4Q365a fragments within the column structure of 4Q365. This argument requires careful consideration, as it would provide previously overlooked physical evidence against inclusion of the 4Q365a fragments with 4Q365. Yet close examination of the arguments Crawford brings reveals that they do not substantially change the picture.

Crawford rightly turns attention to the question of where the 4Q365a fragments might fit in the manuscript context of 4Q365, if we propose that 4Q365 and 4Q365a do belong together. She begins by noting Strugnell's tentative placement of all of the 4Q365a fragments right after 4Q365 fr. 23. His reason for this placement was what he perceived as a topical similarity: 4Q365 237 mentions the Passover sacrifice, while 4Q365a 12 refers to the festival of Unleavened

${ }^{21}$ Armin Lange regards as decisive the similarity, first observed by Stegemann in an unpublished 1994 lecture, between the creases on 4Q365 fr. 6 and 4Q365a fr. 2: such similar damage patterns mean the two fragments must have come from the same manuscript. See Lange, Handbuch, 40 (I owe this reference to Crawford, "4QTemple? Revisited," 88); also Daniel K. Falk, The Parabiblical Texts: Strategies for Extending the Scriptures among the Dead Sea Scrolls (London: T\&T Clark, 2007), 109. Charlesworth, who has recently defended the separation of the 4Q365a fragments from 4Q365, nonetheless accepts that the physical evidence suggests that both were part of a single ms. He notes that there are other cases at Qumran of two different compositions being copied on a single ms, though the only example he cites is the case of the related compositions 1QS, 1QSa, and $1 \mathrm{QSb}$ (Charlesworth, "4Q365a," 235). Tov lists only three other possible cases of multiple compositions written on a single scroll by a single hand; in all three cases the evidence is fragmentary. See Emanuel Tov, Scribal Practices and Approaches Reflected in the Texts Found in the Judean Desert (STDJ 54; Leiden: Brill, 2004), 39. The rarity of this occurrence suggests that unless concrete evidence exists for the presence of two different compositions, we should try to make sense of fragmentary mss as containing single compositions. Related to this point, Falk notes the general similarity of content between the 4Q365a frs and, e.g., the expanded festival commands in 4Q365 fr. 23 (Parabiblical Texts, 108).

${ }^{22}$ Crawford, "4QTemple? Revisited” (see n. 14 above). 
Bread. Crawford argues that, while it makes some sense to join 4Q365a fr. 1 with 4Q365 fr. 23, there are also other places it could have been located. The other fragments of 4Q365a, on the other hand, are unlikely to have belonged after 4Q365 fr. $23 .{ }^{23}$

For most of the fragments of 4Q365a, Crawford's analysis is inconclusive: she considers possible locations for frs 1, 3, 4, and 5 but notes that there is no clear evidence for or against any particular placement within the larger structure of $4 \mathrm{Q} 365 .{ }^{24}$ The crux of the argument lies with 4Q365a fr. 2, a large fragment with parts of two columns containing instructions for building a temple court that correspond closely to TS cols 38 and 41 . The question becomes, where might such instructions have fit within the narrative structure of the Pentateuch? Because of similarities in style and content (building instructions phrased in the $2^{\text {nd }}$ person), Crawford suggests that we might expect this fragment to belong "in the vicinity of" the instructions for the tabernacle in Exodus $25-30 .{ }^{25}$ However, Exodus $25-30$ and 36-40 are fairly well-preserved in 4Q365, and Crawford notes that the arrangement of the fragments when they were originally brought to the Rockefeller Museum only permits one possible location for the two columns of 4Q365a fr. 2 in this context: between Exod 29:22 (fr. 9 ii) and Exod 30:37 (fr. 10). ${ }^{26}$ This placement, however, would not appear to be the most logical: as Crawford observes, there is no strong topical connection between the materials in Exodus 29-30 (priestly ordination, the incense altar, etc.) and the instructions for the temple courts found in $4 \mathrm{Q} 365 \mathrm{a}$ fr. 2. If instructions for temple courts

${ }^{23}$ Crawford, "4QTemple? Revisited," 91. Note that Crawford bases this judgment on "the physical characteristics of the fragments" (ibid.). There does not, however, seem to be strong physical evidence against the placement of any of the 4Q365a fragments after 4Q365 fr. 23 (= Lev 23:42-24:2 + addition). It is true that fr. 24 (= Lev 25:7-9) preserves a top margin, as does fr. 23. But we simply do not know how many columns might have separated frs 23 and 24. They might represent successive columns (as Crawford suggests on p. 92), but there might theoretically have been any number of intervening columns. Another possible reason for suggesting that the 4Q365a fragments should not be placed here is their content: it is not obvious why instructions for temple courts might be placed in the middle of the Holiness Code.

${ }^{24}$ Crawford, "4QTemple? Revisited," 92-94.

${ }^{25}$ Crawford, "4QTemple? Revisited," 92.

${ }^{26}$ Crawford, "4QTemple? Revisited," 93. 
were placed in the context of the tabernacle narrative, it would make more sense for them to be placed either after the instructions for the tabernacle structure itself are completed (i.e., after Exodus 27), or after the end of the complete body of regulations for the tabernacle and the priestly investiture of Aaron (i.e. after Exodus 30 or 31). Since these placements do not appear to be materially possible, Crawford briefly considers other possible locations (e.g., after the dedication of the tabernacle altar in Num 7:1-88, or in the context of the centralization command in Deuteronomy 12). She concludes, however, that "there is no material evidence... which would support those placements."27

Crawford's comments regarding the original arrangement of the fragments are based on notes and oral communication from Strugnell (their initial editor), and thus their accuracy can no longer be verified. Assuming this analysis is correct, it seems that the largest of the 4Q365a fragments cannot have been located in one place where it might make sense to locate it. The material remains of 4Q365, however, are far too fragmentary to cast any serious doubt on the possibility of placing the 4Q365a fragments somewhere among them. Crawford implies throughout her article that lack of material evidence that a fragment belongs in a particular place could constitute evidence that it might not belong to the manuscript at all. This is true, of course, but this evidence is basically neutral: there is equally no material evidence against a given placement in most cases. A brief exercise in speculation should illustrate this.

There are two basic questions from which we must begin. The 4Q365a fragments appear to contain instructions relating to the building of the courts of a temple. It is probably a safe assumption that they were originally accompanied by instructions for building the temple itself. ${ }^{28}$

${ }^{27}$ Ibid.

${ }^{28}$ See the references to "the house that you shall build" in 4Q365a 31 and 4Q365 236 (this last, occurring as it does in 4Q365, is a small piece of evidence linking 4Q365 on the basis of content with the building instructions in the 4Q365a fragments). 
For the purposes of our speculation, it is also probably safe to treat the five fragments as a unit, since all but one of them explicitly contain building terminology. ${ }^{29}$ The first basic question is, where in the context of the Pentateuch might these instructions possibly have been located? The second question is, how many of those theoretically possible placements would be materially possible within $4 \mathrm{Q} 365 ?^{30}$

Aside from considerations of content, narrative voice provides one of very few clues as to where the 4Q365a fragments might belong within the context of the Pentateuch. The evidence is not extensive, but at various points in this group of fragments Israel appears to be referred to in the $3^{\text {rd }}$ person. ${ }^{31}$ The fragments also contain several examples of $2^{\text {nd }}$-person singular address, including the phrases ואמרתה [א]ליזהם, "speak to them"(4Q365a 1 4); "you shall make" (4Q365a 2 ii 7) הבית אשר תבנה "ה2, "the house that you shall build" (4Q365a 3 1). These examples suggest that the instructions in 4Q365a are depicted as being spoken by God to Moses. This voicing suggests that we should probably not place these fragments within the context of Deuteronomy, since Deuteronomy generally presents Moses speaking to the Israelites rather than God speaking to Moses.

Though Deuteronomy can probably be ruled out, the voicing of the temple instructions as commandments of God to Moses would theoretically allow them to be placed nearly anywhere within the books of Exodus-Numbers. As Crawford notes, a location proximate to the instructions for the tabernacle makes a good deal of sense. Though she has shown that the temple

${ }^{29}$ Fr. 1 does not clearly contain building language, referring instead in its legible portions to the festival of Unleavened Bread and a burnt offering of lambs. However, TS shows that sometimes content pertaining to festivals and sacrifice could occur in the context of instructions for building the temple and its courts (e.g. TS 37:10-11, 14; $38: 10 ; 42: 13-17)$.

${ }^{30}$ For speculation as to why a scribe might have been interested in inserting divine instructions for a future temple into the Pentateuch, see Molly M. Zahn, "The Problem of Characterizing the 4QReworked Pentateuch Manuscripts: Bible, Rewritten Bible, or None of the Above?," DSD 15 (2008): 315-339, at 335-37.

31 4Q365a 14 ואמרתה [א]לילהם, "speak to them"; 4Q365a 2 i 2 ישראל, "children of Israel”; 4Q365a 2 i 6 והיו אוכלים, "and they shall be eating."

32 Note that, because of the parallel in TS 41:17, the reading תעשה is certain. 
instructions cannot have been located immediately after the instructions for the tabernacle (i.e. after Exodus 27, or even 30 or 31), there are other possibilities. The temple instructions could theoretically have been placed between the books of Exodus and Leviticus, for instance: since God speaks to Moses from the tent of meeting in Lev 1:1, one could imagine that another divine speech containing the temple instructions could have been slotted in just prior to this, immediately following the account of the consecration of the tabernacle in Exodus 40. One could even make the argument that the temple instructions could have been placed before the instructions for the tabernacle, in Exodus 25. (The logic would be: "Here's what I ultimately want you to do once you're in the land [temple instructions], but in the meantime here's what you should do: [tabernacle instructions, Exodus 25-27].”) Other possible placements might include after the sacrificial instructions in Leviticus (e.g., after Leviticus 7), or prior to the festival legislation in Leviticus $23,{ }^{33}$ or somewhere in the early part of Numbers, or even after the end of Numbers, before Moses' address to the people in Deuteronomy begins. ${ }^{34}$ The relative lack of clear sequence that marks most portions of the pentateuchal legal corpus would seem to present numerous options for an editor seeking to expand the Pentateuch by means of a major "new" set of divine instructions addressed to Moses..$^{35}$

${ }^{33}$ The addition on the wood offering in 4Q365 fr. 23 refers to "the house that you will build for me in the land" (line 6). This might be interpreted as evidence that the instructions for the temple appeared prior to this point in 4Q365. It would probably be unwise, however, to place too much of a burden on this single reference, which may simply be proleptic.

${ }^{34}$ From a synchronic perspective, an insertion of temple instructions just prior to the beginning of Deuteronomy would provide a better sense of the nature of the "place that YHWH your God will choose" that is referred to throughout Deuteronomy. It is worth noting that another Qumran text, 1Q22 (= Divre Moshe/1QapocrMosesa?), appears to insert a divine speech to Moses into the context of the early verses of Deuteronomy. For a new analysis, see Ariel Feldman, "Moses's Farewell Address According to 1Q22 (Words of Moses)," JSP (forthcoming). I am grateful to Dr. Feldman for sharing a copy of his article with me prior to publication.

35 The question might be raised whether it is likely that detailed instructions for a temple would be inserted into a manuscript that already contained detailed instructions for the construction of the desert tabernacle. To my mind, the contents of the Pentateuch even in its traditional, MT form provide the answer. Read synchronically, the Torah's multiple law collections frequently repeat and stand in tension with one another, and the imagined setting in which the laws are to be carried out shifts between the "immediate" location of the Israelites in the wilderness and 
My point here is not to make an argument that any one of these potential locations is more likely than others, or to rule out other possibilities. Rather, it is to stress that there are multiple theoretically possible locations within the Pentateuch for the content implied by the 4Q365a fragments. Equally important is the fact that all of the possibilities mentioned above are also materially possible given the fragmentary remains of 4Q365. There are large gaps in the manuscript between Exod 18:13-16 (fr. 7) and 26:34-36 (fr. 8); and between Exod 39:17-19 (fr. 13) and Lev 11:1 (fr. 14). Thus, a major insertion before or after the tabernacle section, or after the sacrificial instructions of Leviticus 1-7, could be accommodated. Nothing is preserved prior to fr. 23 (Lev 23:42-24:2 + addition) for several chapters, back to small parts of Leviticus 18 in fr. 22. Fr. 26 appears to preserve the transition from Leviticus to Numbers, so a major insertion here is not possible, but the remains from elsewhere in Numbers are quite small, making a placement materially possible at several points here as well, including at the end of the book.

Given this evidence (or, more properly speaking, lack of evidence), Crawford's observations concerning frs 8-12 do not substantially decrease the likelihood that the 4Q365a fragments could have found a home in 4Q365. Of course Crawford is correct that there is no positive evidence for where the fragments should be placed, but given the extremely fragmentary nature of the manuscript and the dearth of evidence for its column structure, this should not surprise us. It is worth keeping in mind that, were it not for the pentateuchal content of most of the 4Q365 fragments, we would have little idea how to place them in relation to each other, either (and indeed, ordering them according to the sequence of the Pentateuch involves the assumption that they generally followed that sequence!). In the end, since they clearly could have

the anticipated "future" settlement in the land. For example, the priestly laws of Leviticus 1-16 refer to the tent of meeting as the principle site of their enactment, while the laws of the Holiness Code and Deuteronomy are frequently marked as intended for future application through the locution "when you come into the land..." and related phrases (see e.g. Lev 19:23; 25:2; Deut 17:14; 18:9). 
fit somewhere in 4Q365, the issue of the placement of the 4Q365a fragments does not raise new arguments pertaining to the relationship between 4Q365a and 4Q365. That leaves us with the observations regarding hand and leather made by Strugnell and others. As noted above, the physical evidence strongly suggests that the fragments of 4Q365 and those of 4Q365a belong together.

4QRP C $(=4 Q 365+365 a)$ as a Copy of the Pentateuch

Although 4QRP C, like the rest of the 4QReworked Pentateuch manuscripts, was originally (and remains officially) classified as a "parabiblical text," it now seems most likely that it was composed as a "normal," authoritative copy of the Torah. ${ }^{36}$ Most scholars would now tend to support the idea that "4QPentateuch $C$ " is a more appropriate label for 4Q365 than "4QReworked Pentateuch C." ${ }^{37}$ However, considerations of this issue have tended not to explicitly discuss 4Q365 + 4Q365a, that is, 4QRP C as a Pentateuch containing multiple columns of added instructions for the building of a temple and its courts. ${ }^{38}$ Scholars who may be comfortable labeling 4Q365 as a copy of the Pentateuch, with its relatively moderate extant additions (all less

${ }^{36}$ See e.g. Crawford, Rewriting Scripture, 56.

${ }^{37}$ One of the earliest voices calling for this change was that of Eugene Ulrich, "The Dead Sea Scrolls and the Biblical Text," in The Dead Sea Scrolls after Fifty Years: A Comprehensive Assessment (ed. P. W. Flint and J. C. VanderKam; 2 vols.; Leiden: Brill, 1998), 1.79-100, at 88. See also James C. VanderKam, "Questions of Canon Viewed through the Dead Sea Scrolls," in The Canon Debate (ed. L. M. McDonald and J. A. Sanders; Peabody, Mass.: Hendrickson, 2002), 91-109; Michael Segal, "4QReworked Pentateuch or 4QPentateuch?," in The Dead Sea Scrolls: Fifty Years After Their Discovery (ed. L. H. Schiffman, E. Tov, and J. C. VanderKam; Jerusalem: Israel Exploration Society/Shrine of the Book, Israel Museum, 2000), 391-99. More recently Emanuel Tov has also endorsed this perspective in a number of publications; see e.g. "From 4QReworked Pentateuch to 4QPentateuch (?)," in Authoritative Scriptures in Ancient Judaism (ed. M. Popović; JSJSup 141; Leiden: Brill, 2010), 73-91. A dissenting voice arguing that the 4QRP mss are not likely to constitute scriptural texts is Moshe J. Bernstein, “'Rewritten Bible': A Generic Category Which Has Outlived Its Usefulness?,” Textus 22 (2005): 169-96, at 18283.

${ }^{38}$ For instance, in a recent article, Tov notes that there are two manuscripts of TS from Cave 4 . Though he does not specify which manuscripts he means, the only Cave 4 manuscript even preliminarily identified with TS besides 4Q524 (4QRT) is 4Q365a. This seems to indicate that Tov, though he now views 4Q365 as "Pentateuch" rather than "Reworked Pentateuch," continues to regard the 4Q365a fragments as belonging to a separate composition. See Emanuel Tov, "The Authority of Early Hebrew Scripture Texts," Journal of Reformed Theology 5 (2011): 276-95, at 293. An exception to this general trend is Lange, Handbuch, 37-40. As noted above (n. 12), Lange regards 4Q364-367 as pentateuchal, and also views 4Q365 as properly including the 4Q365a fragments. 
than ten lines), may feel differently when faced with so much new material. The question is, then, whether 4QRP C is less likely to have constituted a copy of the Pentateuch if it originally contained the 4Q365a materials.

Crawford, for instance, notes that taking the 4Q365a fragments as part of 4Q365 would “change the nature of 4Q365, making it less like an expanded Pentateuch and more like a more extensively rewritten composition such as Jubilees." 39 Though she does not say so directly, this statement implies that she would be less likely to regard 4Q365 as a copy of the Pentateuch if it originally contained the 4Q365a fragments. I am not convinced, however, that this conclusion is warranted. I do not think there is sufficient evidence to support the assumption that a large, multiple-column addition to the text of the Pentateuch would be enough to "disqualify" it from constituting a copy of the Pentateuch in the eyes of ancient readers. After all, the LXX of Jeremiah is some $17 \%$ shorter than the MT version. ${ }^{40}$ The evidence of 4 QJer ${ }^{\mathrm{b}, \mathrm{d}}$ indicates that this shorter text represents a Hebrew version of Jeremiah, and it seems that no distinction in authority was made between them. ${ }^{41}$ The literary history of the books of Daniel and Esther may offer another relevant comparison, insofar as their Greek versions each contain several completely new sections not found in their Hebrew versions. ${ }^{42}$ Various objections could be made to such comparisons, e.g. that multiple versions of prophetic books is one thing but multiple versions of the Torah is another; or that such a large insertion is simply "too much" change for a copy of the

${ }^{39}$ Crawford, "4QTemple? Revisited," 93.

${ }^{40}$ Emanuel Tov, Textual Criticism of the Hebrew Bible ( ${ }^{\text {nd }}$ ed.; Minneapolis: Fortress, 2001), 320.

${ }^{41}$ Eugene Ulrich, "Pluriformity in the Biblical Text," in idem, The Dead Sea Scrolls and the Origins of the Bible (Grand Rapids: Eerdmans, 1999), 79-98, at 93; Armin Lange, "The Status of the Biblical Texts in the Qumran Corpus and the Canonical Process," in The Bible As Book (ed. E. Herbert and E. Tov; London: British Library, 2002), 21-30, at 27; Michael Segal, "Between Bible and Rewritten Bible," in Biblical Interpretation at Qumran (ed. M. Henze; Grand Rapids: Eerdmans, 2005), 10-28, at 14; more recently Ulrich, "Methodological Reflections on Determining Scriptural Status in First Century Judaism," in Rediscovering the Dead Sea Scrolls (ed. M. L. Grossman; Grand Rapids: Eerdmans, 2010), 145-61, at 149; and Tov, "Early Hebrew Scripture Texts," 287.

${ }^{42}$ Emanuel Tov, "Three Strange Books of the LXX: 1 Kings, Esther, and Daniel Compared with Similar Rewritten Compositions from Qumran and Elsewhere," in idem, Hebrew Bible, Greek Bible, and Qumran (TSAJ 121; Tübingen: Mohr Siebeck, 2008), 283-308. 
Torah to undergo and keep its status as a copy of Torah. In the end, however, we know that multiple versions of scriptural texts (including books of the Torah) could circulate simultaneously, and that sometimes the differences between these versions could be substantial. ${ }^{43}$ We do not know, however, what sort of limits there were to such differences; where the line was drawn beyond which a revised or expanded text no longer could be viewed as a "copy" of the same text. ${ }^{44}$ Given this situation, I find it very difficult to justify the assumption that 4QRP C (4Q365 + 365a) could not have been regarded as a copy of the Torah. Instead, it seems necessary to explore all the possibilities regarding this text's production and use, including the possibility that it was produced and received as scripture, and used as a scriptural source by the author of TS.

\section{The Relationship Between 4QRP C and TS}

As mentioned briefly above, the key evidence for a literary relationship between 4QRP C and TS is the similarity in content at two points. 4Q365a fr. 2 presents parts of two columns (col. $\mathrm{i}=10$ lines; col. $\mathrm{ii}=11$ lines) that contain major overlaps with TS cols 38 and 41. In fact, 4Q365a 2 ii 1-7 corresponds nearly verbatim to TS 41:5-17 (instructions for the outer court of the temple). The parallels between 4Q365a $2 \mathrm{i}$ and TS 38 (the end of the commands for the inner

${ }^{43}$ In addition to the works cited above (nn. 41 and 42), see Ulrich, Dead Sea Scrolls and the Origins of the Bible, especially ch. 6, "Multiple Literary Editions: Reflections Toward a Theory of the History of the Biblical Text"; and Emanuel Tov, "The Many Forms of Hebrew Scripture: Reflections in Light of the LXX and 4QReworked Pentateuch," in From Qumran to Aleppo (ed. A. Lange et al.; FRLANT 230; Göttingen: Vandenhoeck \& Ruprecht, 2009), 11-28.

${ }^{44}$ Rather than focusing on a "spectrum" or "continuum" of reworking, it seems preferable to highlight the literary strategies used by authors of rewritten texts to distinguish their work from the works they rewrite (on this issue, see Segal, "Between Bible and Rewritten Bible"; Zahn, "Problem of Characterizing"; and Zahn, Rethinking Rewritten Scripture, 9-11, 239-41). While it makes intuitive sense that, even without these literary strategies, at some point a rewritten text could become too different from the base text to be identified by a reasonable audience as a version of the same composition, the fact remains that we have no evidence for where that point might have lain in the Second Temple period. 
court and beginning of the commands for the middle court) are substantial, but less precise. ${ }^{45}$ Of course it is not possible to determine exactly how far the parallels between TS and 4Q365a continued (if at all) beyond what is extant in fr. 2. However, Crawford's observation should be noted that, if the space between the end of the extant text of 4Q365a $2 \mathrm{i}$ and the beginning of col. ii is reconstructed according to the missing sections of TS cols 38-41, the result would be a column of approximately 43 lines. ${ }^{46}$ This height would fit well with what little evidence we have for column heights in 4Q365 + 365a: in the two places where column heights can be determined, they come out to 43 lines and 47 lines. ${ }^{47}$ The material evidence thus suggests that 4Q365a fr. 2 largely corresponded to TS also in the lacuna between columns i and ii. $^{48}$

The second overlap in content, as mentioned, pertains to the instructions to bring wood to donate for the functions of the temple in $4 \mathrm{Q} 365 \mathrm{fr} .23 .{ }^{49} \mathrm{In} \mathrm{TS}$, it appears that wood was brought tribe by tribe over the course of a distinct six-day festival that followed immediately after the feast of new oil (cols 21-24). In 4Q365, wood is also brought over a period of several days (the exact number is not preserved, but since it appears that two tribes brought wood each day, six days seems a reasonable conclusion). The extant order of the tribes corresponds to the order of

${ }^{45}$ See White (Crawford), DJD 13:325-29; and, with more detailed reconstruction, eadem, "Three Fragments." I cannot, however, accept Crawford's claim that the text of TS cols 38-41 must have been "much longer" than the parallel passage in 4Q365a 2 i-ii (ibid., 269). In fact, given that 4Q365a 2 ii must have had an average line length of approximately 75-76 letter spaces, there is ample room in this column for the corresponding material from TS. On the likely height of this reconstructed column, see further below.

${ }^{46}$ Crawford, "4QTemple? Revisited," 90.

47 4Q365 6a i = 47 lines; 4Q365 12a-b ii-iii = 43 lines; see Tov and White (Crawford), DJD 13:256.

${ }^{48}$ Citing a column height for TS (11Q19) of 22-29 lines, Crawford uses this reconstruction of a 43-line column in 4Q365a 2 to argue that 365a cannot have matched TS at this point ("4QTemple? Revisited," 90). However, there is no reason to expect that 4Q365 + 365a would have had the same number of lines per column as 11Q19. It is instead the consistency of the proposed 43-line column with the rest of 4Q365 + 365a that suggests that 4Q365a may well have continued to correspond to TS in the gap between the two columns of fr. 2.

${ }^{49}$ For recent discussion of this fragment, see Crawford, Rewriting Scripture, 49-51; Cana Werman, "The Wood-Offering: The Convoluted Evolution of a Halakhah in Qumran and Rabbinic Law," in New Perspectives on Old Texts (ed. E. G. Chazon et al.; STDJ 88; Leiden: Brill, 2010), 151-82, at 155-58; Zahn, Rethinking Rewritten Scripture, 102-8. 
tribes preserved in TS col. 24-an order that is otherwise unattested, even elsewhere in TS. ${ }^{50}$

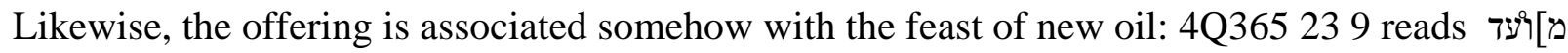

[ היצהר יקריבו את העצים שנים "...the fe]ast of new oil they shall bring the wood, two..."51 In this

case, there is no possibility of extensive textual overlap between TS and 4Q365, since the

material on the wood offering is preceded in TS by detailed legislation on the feast of new oil,

while in 4Q365 it follows directly upon the legislation for the festival of Sukkot from Leviticus

23. ${ }^{52}$ However, the two texts each seem to envision a basically identical procedure in which

wood for the altar is supplied tribe by tribe over the course of several days, sometime around the time of the festival of new oil. ${ }^{53}$

These major correspondences in the instructions for the courts and in the mention of a wood offering suggest some kind of literary relationship between TS and 4QRP C. Of course, in cases like this it can be difficult to determine which text depends upon which, or whether a common source might be involved. Here, the nature of the evidence precludes certainty, but that evidence also suggests that one of the most likely scenarios is that TS is dependent upon the version of the Pentateuch preserved in $4 \mathrm{QRP} C$, or a very similar one. To determine the relative likelihood of this proposal, various alternative possibilities must be considered. ${ }^{54}$

\footnotetext{
${ }^{50}$ We can tell this is the case despite the fact that only three tribe names are preserved in 4Q365 fr. 23 , because the grouping together of Reuben and Simeon on the third day/in fifth and sixth position occurs nowhere else. On the order of the tribes, see Tov and White (Crawford), DJD 13:296; Yadin, Temple Scroll, 1.126.

${ }^{51}$ Besides TS and 4Q365, a "feast of oil" (מועד השמן) is also attested in 4Q394 1-2.

52 See also Crawford, "Three Fragments," 264.

${ }^{53}$ A date for the wood offering is not preserved in TS or in 4QRP C. Its location in TS between the feast of new oil (which can be dated via the calendrical document 4Q394 1-2 to the $22^{\text {nd }}$ of the sixth month) and the "Day of Memorial" (= Rosh Hashanah) leads Yadin to conclude that it probably began directly after the feast of new oil, that is, on the $23^{\text {rd }}$ of the sixth month (Yadin, Temple Scroll, 1.122). Whether any dates were provided in 4QRP C is impossible to determine. However, it should be noted that the section on the wood offering comes after the end of the legislation for Sukkot. Furthermore, the "feast of new oil" is referenced briefly in fr. 23 9, but no details are provided pertaining to that festival. The possibility is worth considering that more extensive legislation for the feast of new oil was introduced in 4QRP C prior to the rules for Rosh Hashanah given in Lev 23:24.

${ }^{54}$ I should clarify here that I do not regard the paleographic dates of the manuscripts themselves as a significant factor in determining the relationships between the texts they contain, because the age of a manuscript provides only a terminus ante quem for the composition of the work written on it. Thus the fact that the main copy
} 
One of the most obvious alternatives would be to see 4QRP C as dependent upon TS rather than vice-versa. ${ }^{55}$ In this regard, one key point is that 4QRP C parallels two different sections of TS (cols 22-23 and cols 38-41), on two different topics (the wood offering and instructions for the temple courts), but contains no other clear points of contact with TS, including in the other 4Q365a fragments that contain building instructions. If 4QRP C drew upon TS, it is difficult to understand why it would have used TS in just these two different places but, apparently, nowhere else. Also, 4QRP C appears to lack the exclusively legal focus of TS. ${ }^{56}$ Although the precise extent of its contents cannot be determined, it definitely includes a great deal of narrative material in which TS shows no interest. ${ }^{57}$ Of course the editor of 4QRP C could theoretically have drawn on the rewritten law of TS on specific issues. But since we know that TS does rework the Pentateuch, it seems more probable that TS drew on the Pentateuch as represented in 4QRP C, rather than that it drew on another version of the Pentateuch and then in turn was drawn upon by the expanded Pentateuch 4QRP C. ${ }^{58}$

Another possible explanation for the literary relationship between TS and 4QRP C is that each drew upon a common source. This possibility is particularly interesting in light of the dominant proposal that TS comprises several pre-existing literary sources. The two points of contact between TS and 4QRP C in fact occur in sections of TS that the standard model

of TS, 11Q19, is paleographically later than $4 \mathrm{QRP} C$ does not preclude the possibility that $4 \mathrm{QRP} C$ draws upon TS, since 11Q19 could be (and almost certainly is) a copy of an earlier manuscript. Likewise, the paleographic dating of 4Q524 (4QRT) earlier than 4QRP C does not mean that TS could not have used the version of the Pentateuch represented by 4QRP C as a source, even if 4Q524 is to be regarded as an early recension of TS (on the difficulties with this view, see Charlesworth, "4Q524," 249-52). It would simply mean that 4QRP C is a relatively faithful copy of an earlier pentateuchal manuscript with the same essential features. 4Q524 dates from the last half of the second century BCE (Charlesworth, "4Q524," 248), 4QRP C dates to ca. 75-50 BCE (Lange, Handbuch, 41), and 11Q19 dates to ca. 25 BCE-25 CE (Crawford, Temple Scroll, 12).

${ }^{55}$ See Wacholder, Dawn of Qumran, 206, though he assumes rather than argues for this position.

${ }^{56}$ On the issue of the treatment of law in the 4QRP mss, see Moshe J. Bernstein, "What Has Happened to the Laws? The Treatment of Legal Material in 4QReworked Pentateuch," DSD 15 (2008): 24-49.

${ }^{57}$ It is generally assumed that 4QRP C covered the entire Pentateuch, and the distribution of the fragments across all five books supports this assumption, but the state of the manuscript does not allow any concrete assessment of its scope. See Zahn, "Problem of Characterizing," 331-32.

${ }^{58}$ See further Zahn, Rethinking Rewritten Scripture, 100 n. 56. 
attributes to two different sources: the material on the wood offering is classified as part of the "Festival Calendar" source, while the instructions for the courts belong to the so-called "Temple Source." 59

The evidence of 4QRP C at the very least introduces some complications into this sourcecritical analysis of TS. First of all, the differences between TS and 4QRP C regarding the legislation for both the wood offering and the temple and its courts suggest that, if there were one or more existing source(s) that contained this material, they may have looked considerably different from either extant manuscript. That is, 4QRP C or TS or (likely) both may have substantially changed their source in the course of incorporating it. This should not surprise us, given the frequent changes that both texts make to sources known to us from the Hebrew Bible. It means, however, that except in the few cases of close agreement between 4QRP C and TS there is very little we could say with precision about the content, much less the wording, of these prior sources.

Secondly, the fact that TS parallels $4 \mathrm{QRP} C$ in sections generally attributed to two different sources means that we must hypothesize either that 4QRP C happened to draw on the same two sources independently of TS, or that these sources were already combined prior to their use by both TS and 4QRP C (or that they originated together and were never in fact separate sources). Use by two different later texts of the same two independent sources is of course not impossible, but seems a rather unlikely coincidence. Use of a single source (here, one combining temple instructions with festival legislation) by two different texts is more plausible.

This hypothetical scenario in which two sources (i.e., sections of text on a specific topic) were already combined and then used by the composers of both TS and 4QRP C pushes us towards a more economical solution. If the composer of TS found instructions for a temple and

${ }^{59}$ See e.g. Wilson and Wills, "Literary Sources,” 275; Crawford, Temple Scroll, 34, 49. 
its courts and aspects of an expanded festival calendar already combined in a preexisting text, it seems very plausible that this text could in fact have been an expanded Torah closely resembling 4QRP C. ${ }^{60}$ In this manuscript we have a text that already contains instructions for the building of a temple in the land, and refers to the festival of new oil and the wood offering, two of the three new firstfruits festivals mentioned in TS. ${ }^{61}$ 4QRP C also appears to have contained a version of Deuteronomic law, though only one small fragment from Deuteronomy 12-26 is actually extant. ${ }^{62}$ It thus preserves parallels to three of the five main sections or sources usually postulated for TS: the Temple Source, the Festival Calendar, and the Deuteronomic Paraphrase. The differences between 4QRP C and TS would be due to the fact that the composer of TS would not always have taken over source material verbatim. Just as TS makes considerable changes in the course of its reuse of pentateuchal texts known to us, the composer would have made considerable changes to the temple/court and festival instructions he found in 4QRP C, shaping them to fit his own particular ideological perspective. ${ }^{63}$

\footnotetext{
${ }^{60}$ Wise in fact proposed that several of the 4Q365 / 4Q365a fragments constituted a "proto-TS" in which the Deuteronomy Source (to which he attributed 4Q365 fr. 23) and the Temple Source were already combined (Critical Study, 59). However, since Wise wrote before the full publication of 4Q365 / 4Q365a, his theory was developed solely on the basis of the three fragments on PAM 43.366 that Yadin had identified as an additional copy of TS ( = 4Q365 fr. 23; 4Q365a frs 2 and 3).

${ }^{61}$ The third is the feast of new wine; TS cols 19-21.

${ }^{62}$ Fr. 38 preserves Deut 19:20-20:1.

${ }^{63}$ Theoretically speaking, additional evidence that a text like 4QRP C could have been the pentateuchal source for TS might be found in a detailed analysis of the text-critical relationships of the two texts. That is, the case for a close relationship would be strengthened if TS and 4QRP C shared small variant readings, in addition to the major parallels analyzed above. However, the fragmentary nature of the manuscripts means that in reality the textual basis for such an analysis is very slight. Even when 4QRP C and TS appear to be reproducing the same pentateuchal text — itself a relatively rare occurrence — any actual extant overlap is never more than a few words. I have counted only 7 instances where 11Q19 appears to draw upon a specific verse that is also partially extant in 4QRP C (none of the other manuscripts associated with TS contain any additional overlaps). In three of these cases there is no variation between 11Q19, 4QRP C, MT, and SP (Lev 11:44 // 4Q365 174 // 11Q19 51:7; Deut 19:21 // 4 Q365 382 //11Q19 61:12; Deut 20:1 //4Q365 383 // 11Q19 61:12-13). In one case 11Q19 and 4QRP C follow SP against MT (Deut 19:20 // 4Q365 $381 / / 11 \mathrm{Q} 19$ 61:11). In one case all four witnesses differ, but 4QRP C's reading is closer to that of TS than MT and SP (Lev 11:22 // 4Q365 155 // 11Q19 48:4). In the remaining two cases, 4QRP C follows MT while TS differs, but both of these cases involve extensive reworking on the part of TS; therefore, the variants are very likely to have been introduced by the redactor of TS (Exod 29:20 // 4Q365 9b ii 1// 11Q19 16:3; Exod 36:36 // 4Q365 12a i 5 // 11Q19 12:15). Such paltry evidence does little to enhance the evidence for a connection between TS and 4QRP C, but neither does it argue against such a connection.
} 


\section{Conclusion: The Literary History of TS}

The goal of this study has been to suggest that, instead of the dominant model of the Temple Scroll as composed from the combination of originally independent prior sources, another possible model is at least as likely: that of an author or editor working with an already substantially expanded and reworked form of the Torah, similar to what we find in 4QReworked Pentateuch C. That is, 4QRP C could have constituted the source for TS's rewriting of "pentateuchal" material as well as the source for some of its major "nonbiblical" innovations. TS, in this model, is less a patchwork of independent sources, however creatively adapted and integrated, than a wholesale refiguring of an already revised and expanded form of the pentateuchal legal tradition. This suggestion constitutes a sort of middle ground in the context of recent work on the Scroll: the redactor of TS worked primarily with the Torah as opposed to making use of a number of preexisting sources; however, this Torah was not simply identical to the MT (or any other known version), but a version that contained numerous variant readings, including major expansions. ${ }^{64}$ If the redactor drew on a text like 4QRP C, he would not have been responsible for all of the so-called "nonbiblical" material in the Scroll, but neither would he have cobbled this material together from various independent sources.

Despite my suspicion of the source-critical approach to TS as it has typically been articulated, I would not wish to deny any possibility that the redactor used multiple sources. If we have learned anything from the Qumran corpus about the production and transmission of texts, it is that it was a multifaceted process that is difficult for us to chart with confidence. ${ }^{65}$ Of

\footnotetext{
${ }^{64}$ Contra especially Paganini, Rezeption, who seeks to explain virtually every difference between TS and MT as a deliberate change on the part of TS.

${ }^{65}$ Especially in need of further study in this regard is 4Q524, which overlaps at several points with nonpentateuchal material in 11Q19 but fails to parallel 11Q19 precisely or, in some cases, at all. 4Q524 has variously
} 
course it is not out of the question that the redactor would have inserted individual elements or sections drawn from other texts than his main Vorlage. Furthermore, even if 4QRP C or a similar text was the immediate source of some of the new material in TS, this does not mean that that source text (4QRP C or related) was necessarily the original textual context of this new material. The feasts of the firstfruits of wine and oil, for example, as well as the wood offering, seem clearly to derive from exegetical extrapolation of scriptural texts. But it is possible that such stipulations first took written form in a calendrical document that circulated independently, and only later were incorporated into a rewritten version of Torah like 4QRP C. A similar scenario is certainly possible with regard to the temple- and court-building instructions.

Although various types of sources can be postulated, however, we have no clear evidence for the prior independent existence of any part of TS or of 4QRP C. ${ }^{66}$ On the other hand, we have ample evidence that at least some Second Temple scribes were willing to alter scriptural texts dramatically in the course of their transmission and that the production of new texts through rewriting of existing texts was common practice. We also know that the techniques used to reshape scripture in TS are essentially the same as those used in texts like the 4QRP mss and the Samaritan Pentateuch. ${ }^{67}$ It thus makes sense to postulate that TS originated in this same context

been construed as a recension of TS very similar to 11Q19; a significantly different, likely earlier, recension of TS; or a source used by the compiler of TS; see Charlesworth, "4Q524," 249-50.

${ }^{66}$ Perhaps the strongest argument for the existence of any of the postulated sources is the one Schiffman offers pertaining to the Law of the King (TS 56:12-59:21). He notes that, contrary to the redactor's usual practice of gathering all material pertaining to a single topic around its first occurrence, laws on warfare occur in the Law of the King but then also later when TS reproduces Deuteronomy 18-22 in cols 60-66. See Lawrence H. Schiffman, "The Laws of War in the Temple Scroll," in idem, Courtyards of the House of the Lord (n. 6 above), 505-17. Schiffman's argument is weakened, however, by the fact that the redactor does not seem to have used this procedure consistently: in cols 62-63 the law on a body found in an open field has not been removed from its traditional location between sections of laws on war (see Deut 20:1-21:14), nor has the material pertaining to the military in Deut 23:9-14 or 24:5 been grouped together with the other laws on war. Also arguing, contra Schiffman, that the Law of the King represents the work of TS's redactor is Elledge, Statutes, 32-36.

${ }^{67}$ See Zahn, Rethinking Rewritten Scripture, 218-28. 
of the ongoing processes of exegetical reconfiguration and expansion that characterized the transmission of scriptural texts in the Second Temple period. ${ }^{68}$

The common view of TS as made up of various preexistent sources has never fully been reconciled with the scholarly appreciation of the exegetical nature of TS and its place in discussions concerning scriptural rewriting. Nor for that matter has the source-critical model been able to explain fully the literary overlaps between TS and 4Q365 +4Q365a. The reevaluation of 4QRP C presented here opens the way for a model that takes account both of TS's obvious connections to the scribal reworking of scripture and of the empirical evidence for a literary history more complex than a simple engagement with the Torah in its traditional form.

The model I propose is heavily indebted to recent advances in our understanding of the dynamics of Second Temple scriptural transmission. At the same time, as mentioned above, the gist of this model was already suggested thirty years ago by John Strugnell. In retrospect, one can readily see the twists and turns in the history of scholarship that have kept Strugnell's proposal out of the limelight. Before the full publication of 4Q365, it would have been impossible to verify his comments about the nature of the documents. Then, once 4Q365 was published, it was labeled as a parabiblical text, as opposed to a copy of the Pentateuch, andperhaps most critically for future studies - the fragment with the greatest correspondences to TS (4Q365a fr. 2) was assigned to a different manuscript. The effects of these twists and turns in this one case point to issues of broader significance. Though editors may express great uncertainty about the distribution of fragments (e.g., do the 4Q365a fragments belong with 4Q365?) or about the characteristics of certain manuscripts, the fact is that critical editions, lists, and catalogs demand that decisions be made about titles and categories (biblical vs. parabiblical; 4QReworked

${ }^{68}$ This context also allows us to assume that TS, once composed, continued to itself be subject to revision, which may provide a model for understanding the differences between the various mss of the Scroll. 
Pentateuch vs. 4QTemple?; etc.). Once such labels are in place, they tend to become reified and, as a result, to close off interpretive possibilities: it becomes more difficult for subsequent scholars to be aware of the tentativeness with which the original decisions were made and remain open to alternatives. ${ }^{69}$ This case thus challenges all of us who work with the Scrolls to keep in mind the provisional nature of our conclusions, and to continue to reexamine established labels and categories as new information and new perspectives emerge.

${ }^{69}$ It should be noted by way of example that the editors of 4QRP C, Tov and Crawford, have both been more than willing to change their minds regarding several major issues, including whether the ms is "biblical" (see nn. 36 and 37 above). I do not at all mean to imply that the problem lies with editors resisting new interpretations of their texts; rather, it is the very fact of the naming and categorizing that makes it easier for scholars-especially those not involved in the original publication of a text - to overlook the tentative nature of these labels. 